\title{
Introducing Adaptive Analysis Methods: The Present Analysis \& Future Analysis
}

\author{
Kunto Wibowo Agung Prodjonoto \\ Universe War Strategy Program, Indonesian Defense University (UNHAN), Bogor, Indonesia \\ Email: kuntomeruya@gmail.com
}

How to cite this paper: Prodjonoto, K.W.A. (2020) Introducing Adaptive Analysis Methods: The Present Analysis \& Future Analysis. Journal of Analytical Sciences, Methods and Instrumentation, 10, 43-57. https://doi.org/10.4236/jasmi.2020.102004

Received: May 16, 2020

Accepted: June 19, 2020

Published: June 22, 2020

Copyright $\odot 2020$ by author(s) and Scientific Research Publishing Inc. This work is licensed under the Creative Commons Attribution International License (CC BY 4.0).

http://creativecommons.org/licenses/by/4.0/

\section{(c) (i) Open Access}

\begin{abstract}
Mastery of theory, analysis, approach models and decision making, is increasingly important, so finding analytical methods to achieve something better is a logical consequence. For this reason, adaptive analysis method is introduced, which is a method of dynamizing SWOT analysis using commutative properties with the operation of the cross-axis coordinate (X; Y), based on the theory of lines and rules of a sword, phenomenal, natural and relevant, to obtain a grand strategy chosen as a unified strategy like two sides of a coin. The method used is the theoretical and empirical study of adaptive analysis on one of the global issues, namely phenomenal terrorism until now. It is hoped that this method can be used in a variety of problems and is highly determined how a talent plays a role and is not intended to criticize existing analytical methods that have been used.
\end{abstract}

\section{Keywords}

Decision Making, Adaptive Analysis Method

\section{Background}

Problems are getting more complicated and complex, making forecasts of the future more difficult. Therefore, approaches to the mastery of theory, analysis and models of approaches and decision making are increasingly important, so, the search for various methods of analysis to achieve something better is a logical consequence. Among the existing analytical methods that have been used for a long time are the SWOT and TOWS analysis methods, which although these two analytical methods are not analytical tools to solve problems, the SWOT/TOWS analysis approach (Strength, Weakness, Opportunity, Threatness) and the opposite can be evaluated in situations that being faced, which can systematically identify various factors in formulating strategies to deal with it. The SWOT analy- 
sis was created by Albert Humphrey who led a research project at Stanford University in the decade (1960 to 1970) - using data from Fortune 500 companies, while the classic TOWS analysis or known as TOWS-K was first introduced by Professor Heinz Weihrich, the University of San Francisco in 1982 in his article published in the journal Long Range Planning, volume 15, in which the term TOWS is more often used.

SWOT analysis is one of the tools for auditing and analysis, where SWOT can be used at the beginning of the planning process (the present analysis) and TOWS analysis (the future analysis) is used when deciding on future steps. Paying attention to the SWOT matrix (internal-external), it can be mapped on the cross axis (X; Y), so it is also a SWOT matrix, where quadrants I, II, III and IV are as in the SWOT matrix pattern. Therefore, mapping on the cross-axis (X; Y) line through the SWOT matrix analysis process from the results of the IFAS and EFAS tables, can lead to elimination because of the purpose of determining strategic priorities. In general, most people use a score (weight $\times$ rating $=$ score) in conducting a SWOT analysis. However, it does not mean that without a score it cannot be done, because even though it tends to be qualitatively subjective on the simplest model, it can be compared. According to Kurtz (2008, 46), "SWOT analysis is an important strategic planning tool for comparing organizational strengths and weaknesses with external opportunities and threats", whereas the TOWS analysis is a variant of the SWOT Analysis. So, TOWS and SWOT are acronyms for different settings from the words Strength, Weakness, Opportunity and Threats.

Meanwhile, according to Freddy Rangkuti, SWOT analysis is defined as an analysis based on logic that can maximize strengths and opportunities, but simultaneously minimize weaknesses and threats [1], whereas Philip Kotler defines evaluation of all strengths, weaknesses, opportunities and threats [2]. Thus, a SWOT analysis yields a number of alternative strategies, in which to choose these alternatives the organization evaluates one another by paying attention to the ability to achieve the objectives [3].

Furthermore, the author was inspired by the thoughts of Niccolo Machiavelli (1469-1519), a strategist and military political theory and politician from the Republic of Florence. His treatise on sources of the use and limitations of power inspired many military dictators in maintaining his power at that time. The main thoughts of Niccolo Machiavelli include, "involving all state resources in war, including the obligation of all people to participate in fighting until victory is achieved" [4]. In this connection, strenghts and weakness approaches in aspects of internal factors as well as opportunities and threats in aspects of external factors, can easily be seen as a single unit that fights like all inputs. Then, inspired by the theory of strategy in the art of war Sun Tzu, namely: "recognize the enemy and know yourself, then be able to fight in 100 battles without the risk of losing", [5] and "the battle is nothing more than extraordinary and orthodox, but all variations are endless. The extraordinary and orthodox are circular and give birth to one another, because a circle has no beginning. Who can end it? 
[6].”

Recognizing internal factors in SWOT/TOWS analysis means recognizing oneself, while recognizing external factors with opportunities and threats can be interpreted as recognizing enemies or being a party outside oneself or dynamics of environmental situation. As for the relationship, "the extraordinary and the orthodox, but all the variations are endless. Remarkable and orthodox, circular and give birth to each other, because a circle has no beginning", inspires dynamic SWOT analysis as an inexhaustible variation, in terms of input 4 aspects (strengths, weaknesses, opportunities, threats) developed as adaptive analysis, i.e. outputs of two alternative strategies that are mutually binding as a unified strategy like two sides of a coin obtained between 4 alternative grand strategies which are based on 2 strategies which are substance inherent in structure, which can be called a strategy set. So, comprehensively the input is 4 aspects of dynamic processing 6 strategies with output 2 strategies that are mutually binding.

In this connection, it is phenomenal, natural and relevant, that when someone in an internal evaluation states that they have found a number of $S$ strengths and a number of $\mathrm{W}$ weaknesses. Whereas the real power is (S+) or (S-) from what it states, where the sign $(+)$ on the $S$ is empirically seen from most generally over the power that people refer to with the power of the sixth sense which has not occurred, is not evaluated and is not known or not realized. The sign (-) in $S$ is an item that is identified and stated as strength, but it may actually not be the strength. Likewise for the weaknesses of $\mathrm{W}$, when in fact (W+) or $\mathrm{W}(-)$, including $\mathrm{O}$ opportunities and threats $\mathrm{T}$, so unexpected things can happen.

\section{Methods and Theories}

The method used is the task approach method supported by relevant studies and theoretical foundations, interpretive conceptual values include dynamizing the SWOT analysis method which then creates an adaptive analysis method in the scope of theoretical processes and empirical processes in the application of adaptive analysis methods on one of the global issues, namely theoretic phenomenal until now. The review of the relationship or relationship between phenomena and their development is natural, supports the ability to produce innovative things to achieve something better, faced with the present reality which is full of instability, uncertainty, complexity and ambiguity as well as increasingly difficult future forecasts.

\section{Result and Discussion}

\subsection{General}

Theoretically the notion of adaptive in the context of behavior, according to Lambert and Nicoll, 1976, that adaptive behavior is the ability to perform: the function of autonomy; social responsibility; the ability to adapt to people. Then, according to Meyers, et al. (1979), adaptive behavior is "adaptive behavior at the very level referring to a particular exhibited competency in adjustment to the 
culture as expected for high age, in or out of school. To be adaptive in behavior presupposes that one possesses the potential to be adaptive, but the degree and quality of actual adaptive behavior are not idential with potential'. While the adaptive itself according to the Big Indonesian Dictionary [7], is easy to adjust to the situation.

Understanding analysis is an investigation of an event (writing, deeds, etc.) to find out the actual situation (causes, sitting down the case, and so on). So, theoretically it can be concluded that the term adaptive analysis is more of a method used in decomposing a subject matter over its various parts and examining the part itself to get a proper understanding and understanding of the overall meaning as a solution to a problem that begins with an assumption of truth and elaboration after being well studied the best.

\subsection{The Main Points of Adaptive Analysis}

\subsubsection{Commutative Nature}

Basically adaptive analysis implements commutative properties as dynamized SWOT analysis, where commutative properties are the nature of the count operation of two numbers that meet the location of exchanges between numbers so that it produces the same result or in other words, the count operation that satisfies the commutative nature produces the same result, even though where the calculated numbers are exchanged and the commutative nature does not apply to subtraction and division calculation operations. The commutative nature can also be called the commutative law, $\mathrm{a}+\mathrm{b}=\mathrm{b}+\mathrm{a}=\mathrm{c}$ or $\mathrm{a} \times \mathrm{b}=\mathrm{b} \times \mathrm{a}=\mathrm{c}$, where $\mathrm{a}$ and $b$ are 2 numbers that are operated and $c$ is the result of a calculated operation [8]. Thus, a calculated operation that fulfills the commutative nature produces the same result, even though the location of the calculated numbers is exchanged. The commutative nature is as the basis for adaptive analysis, so it does not recognize the reduction arithmetic operations between SWOT aspects both in internal and external factors. Thus, the 4 aspects of SWOT (strengths, weaknesses, opportunities, threats) commutatively become SW, SO (aggressive), ST (diversification), WO (turn around), WT (defensive) and OT $=6$ strategies, where SW on the axis Horizontal is called control strategy and OT on the vertical axis is called challenge strategy and the two strategies (SW and OT) are the strategy sets. SWOT/TOWS = SW; SO; ST; WO; WT; OT, and this is the main point of dynamic SWOT analysis called adaptive analysis, which remains based on the principles of internal and external factors (the opposite), with the essence of control (SW) and challenge (OT) strategy as the substance of the grand strategy structure.

\subsubsection{Numbers Sign Operations on Coordinate Axis (X; Y)}

We know the operation of the number sign [8], positive (+) and negative (-) signs which, when on the cross axis coordinate $(\mathrm{X} ; \mathrm{Y})$, the positive sign $(+)$ is on the number line next to/right from the center of the coordinate axis $(0 ; 0)$ and on the number line above/upward from the coordinate point $(0 ; 0)$ and the negative 
number sign (-) are numbers on the number line next to/to the left of the center axis coordinate $(0 ; 0)$ and the sign the numbers on the number line below/downward from the center of the coordinate axis $(0 ; 0)$.

In connection with adaptive analysis dynamic analysis method $\mathrm{S} \mathrm{W} \mathrm{O} \mathrm{T}$, it uses sign operations on the number line on the cross-axis coordinate (X; Y), so that $\mathrm{S}$ on the horizontal line on the right is marked with a positive number $(+)$. Whereas $\mathrm{W}$ on the horizontal line to the left is marked with negative numbers $(-)$ and $\mathrm{O}$ on the vertical line to the top are positive numbers $(+)$ and $\mathrm{T}$ on the vertical line to the bottom is marked with negative numbers $(-)$. Therefore, in mapping, both IFAS and EFAS where the numbers are positive numbers, it will become a negative number because of the direction on the number line, namely $\mathrm{S}$ positive direction and $\mathrm{W}$ negative direction and $\mathrm{O}$ positive direction and $\mathrm{T}$ negative direction. In this connection, commutatively in SWOT dynamics, it becomes = SW; SO; ST; WO; WT; and OT, where SW is control strategy and OT is challenges strategy, both of which constitute the substance of structure: Aggressive-Defensive (SO-WT) Grand Strategy; Defensive-Aggressive Grand Strategy (WT-SO); Diversification-Turn Around Grand strategy (ST-WO); and Turn Around-Diversification (WO-ST) Grand Strategy, shown in Figure 1.

So the alternative Grand Strategy, are:

1) Obtained alternative strategy choices "Aggressive (SO)" as a result of the meeting point of the longest line/longer $(\mathrm{S})$ and $(\mathrm{O})$, which then as a choice strategy line is drawn from the center of the coordinate axis $(0 ; 0)$. Pay attention to the defensive strategy (WT) as a result of the meeting point of the shortest/shorter lines (W) and (T), which then as the accompanying strategy line is drawn from the center of the coordinate axis $(0 ; 0)$. Therefore, with due regard to the defensive strategy (WT), where the control strategy (SW) and challenges strategy (OT) is essentially the substance of the structure of the Aggressive-Defensive strategy, so the grand strategy of choice is: Grand Strategy Aggressive-Defensive (SO-WT), dominantly and the priority of the Aggressive strategy (SO) that is mutually binding with the accompanying Defensive strategy (WT) priority.

2) Obtained alternative strategy choices "Defensive (WT)" as a result of the meeting point of the longest line/longer (W) and (T), which then as a choice strategy line is drawn from the center point of the coordinate axis $(0 ; 0)$. Keep in mind the aggressive strategy ( $\mathrm{SO}$ ) as a result of the meeting point of the shortest/shorter lines $(\mathrm{S})$ and $(\mathrm{O})$, which then as the accompanying strategy line is drawn from the center of the coordinate axis $(0 ; 0)$. Therefore, with due regard to aggressive strategies (SO), where the control strategy (SW) and challenges strategy (OT) are essentially the substance of the structure of the Defensive-Aggressive strategy, so the grand strategy of choice is: Grand Strategy Defensive-Aggressive (WT-SO), dominantly and the priority of the Defensive strategy (WT) that is mutually binding with the accompanying Aggressive strategy (SO) priority. 


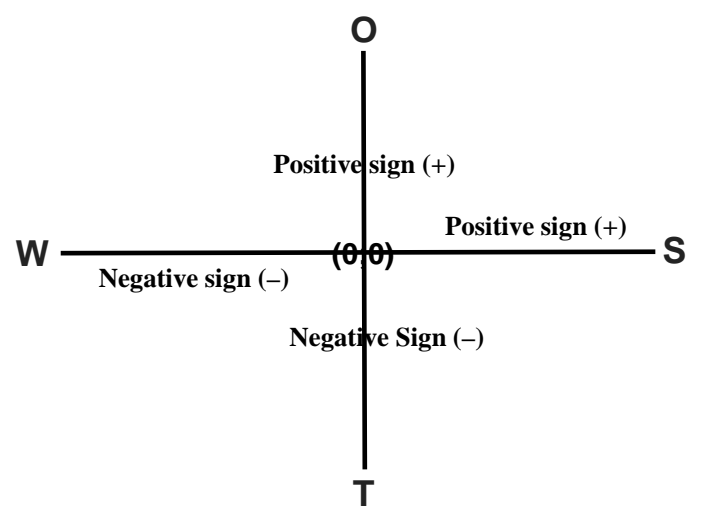

Figure 1. Operation of the number sign on the cross axis coordinates $(\mathrm{X} ; \mathrm{Y})$. Source: data processed by the author.

3) Obtained alternative choice strategy "Diversification (ST)" as a result of the meeting point of the longest/longer line ( $\mathrm{S}$ ) and $(\mathrm{T})$, which then as a preferred strategy line is drawn from the center of the coordinate axis $(0 ; 0)$. Keep in mind the Turn Around strategy (WO) as a result of the meeting point of the shortest/shorter line (W) and $(\mathrm{O})$, which then as the accompanying strategy line is drawn from the center of the coordinate axis $(0 ; 0)$. Therefore, by paying attention to the Turn Around strategy (WO), where the control strategy (SW) and challenges strategy (OT) is essentially the substance of the structure of the Diversification-Turn Around strategy, so that the grand strategy of choice is: Grand Strategy Diversification-Turn Around (ST-WO), dominantly and the priority of the Diversification strategy $(S T)$ that is mutually binding with the accompanying Turn Around strategy (WO) priority.

4) Obtained alternative choice strategy "Turn Around (WO)" as a result of the meeting point of the longest/longer line $(\mathrm{W})$ and $(\mathrm{O})$, which then as the preferred strategy line is drawn from the center of the coordinate axis $(0 ; 0)$. Keep in mind the diversion strategy (ST) as a result of the meeting point of the shortest/shorter line $(\mathrm{S})$ and $(\mathrm{T})$, which then as the accompanying strategy line is drawn from the center of the coordinate axis $(0 ; 0)$. Therefore, by still paying attention to the Diversification strategy (ST), where the control strategy (SW) and challenges strategy (OT) is essentially the substance of the structure of the Turn Around-Diversification strategy, so the grand strategy of choice is: Grand Strategy for Turn Around-Diversification (WO-ST), dominantly and the priority of the Turn Around strategy (WO) that is mutually binding with the accompanying Diversification strategy (ST) priority. Points (3.2.2.a) through (3.2.2.d) are shown in Figure 2.

\subsubsection{Phenomenal, Natural and Relevant}

The implementation is phenomenal, natural and relevant, that adaptive analysis lays the foundation of present and future forecasts, so that it acts as "the present analysis" and "the future analysis". Then, it can be directly mapped into the cross axis coordinate $(\mathrm{X} ; \mathrm{Y})$ and it can be read directly that the longest/longer line 


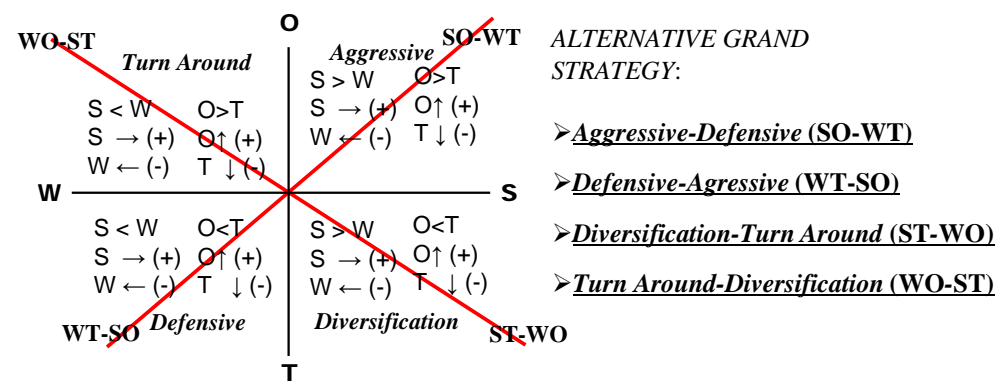

Figure 2. Alternative grand strategy, Source: data processed by the author.

between strengths (S) and weaknesses (W) are drawn from the center of the cross axis $(0 ; 0)$ on the horizontal line (internal) as well as the longest/longer line between opportunity $(\mathrm{O})$ and threats $(\mathrm{T})$ drawn from the center of the cross axis $(0 ; 0)$ on the vertical (external) line, then the displacement of each longest line/longer horizontal line length (internal) $\mathrm{S} / \mathrm{W}$ up/down as far as the vertical line (external) $\mathrm{O} / \mathrm{T}$ and the longest line/longer vertical (external) $\mathrm{O} / \mathrm{T}$ right/left as far as the horizontal line limit (internal) $\mathrm{S} / \mathrm{W}$, the edges are the meeting point of the second end the longest/longer line and that is the end of the dominant strategy line drawn from the central point $(0 ; 0)$ with a fixed magnitude as far as the $\mathrm{X}(\mathrm{S}$ or $\mathrm{W})$ and $\mathrm{Y}(\mathrm{O}$ or $\mathrm{T})$ axes. The dominant strategy line is not the chosen grand strategy, because the meeting of the shortest/shorter end lines on the horizontal (internal) and vertical (external) lines as the intersection of the crossed/diagonal strategy line with the center point $(0 ; 0)$ is a strategy accompanying, so that both strategies are a unified strategy as the chosen grand strategy. Then, in the dominant strategy and accompanying strategy, the results of the evaluation/identification of SWOT aspects can be described, where the greatest score of each is the priority of the strategy (the dominant strategy and the accompanying strategy), so both strategies are priority strategies of the grand selected strategy. Note: the biggest score is obtained from the sum calculation operation of the nominal value not for the purpose of elimination and is not in one line of numbers, so that even on a negative number line, the score is positive (+).

Furthermore, examples of adaptive analysis are illustrative evaluations/identifications in the SWOT analysis previously described. An example is obtained from the IFAS and EFAS as Table 1:

Based on the management of the evaluation/identification results for each SWOT element that has been given a score as in the IFAS and EFAS tables, it can be directly mapped into the cross coordinate axis (X; Y), in Figure 3.

The grand strategy selected is Aggressive-Defensive (SO-WT), which is maximizing strength in maximizing opportunities, while taking into account the minimization of weaknesses to avoid threats, with priority strategies, for example S1 O2 (Max-Max) and W1 T1 (Min-Min), so as to maximize the product produced in utilizing the maximum opportunities not many competitors, by not using too many skilled workers in producing products (standard product quality) or replacing them with production machines that are cheap and adequate for product quality standards to avoid the threat of uncertain market stability. 


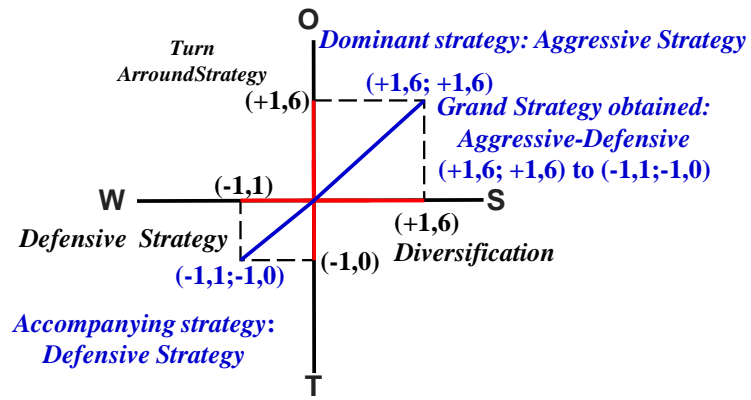

Figure 3. Grand strategy adapative analysis. Source: data processed by the author.

Table 1. IFAS and EFAS tables.

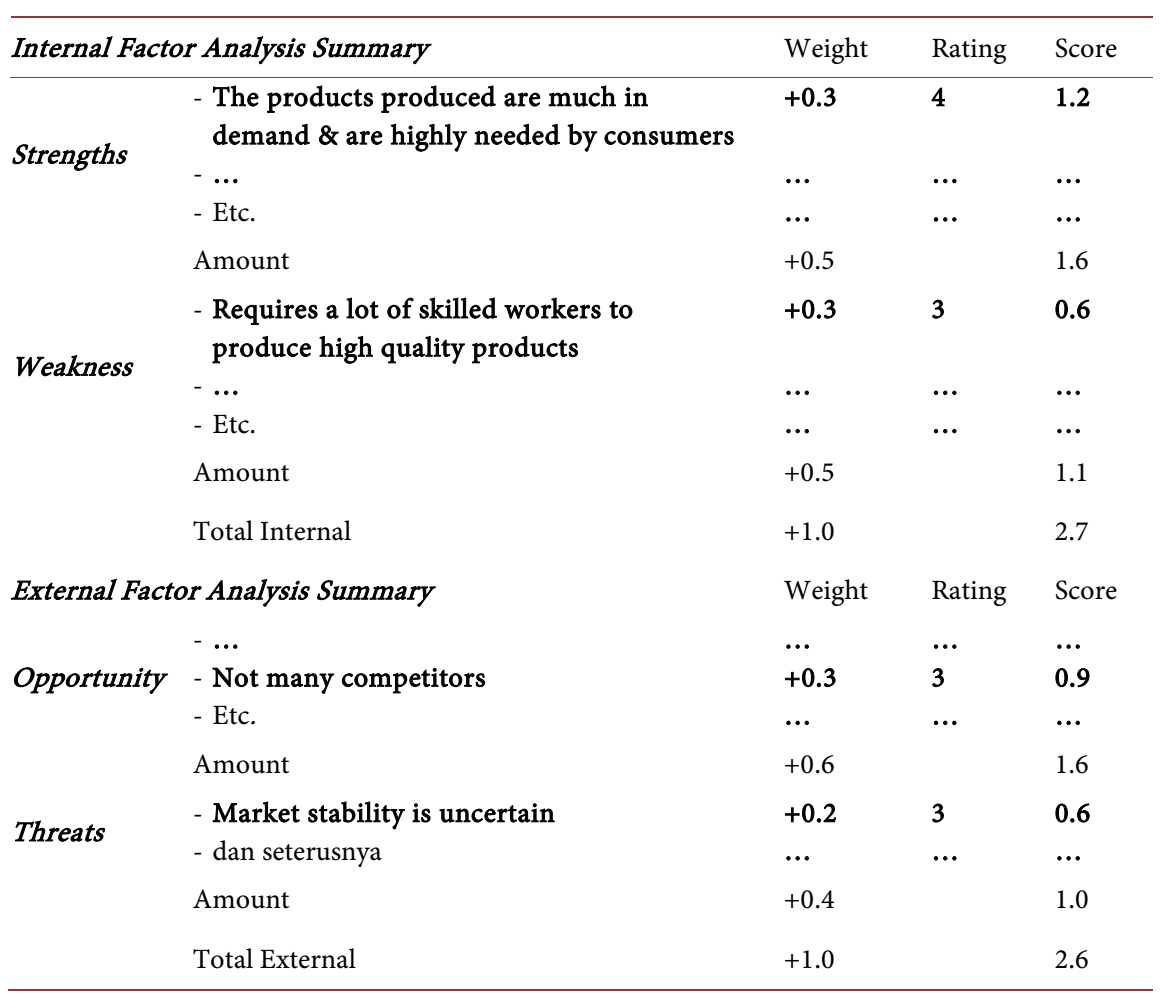

\subsubsection{Rule of a Sword}

Who doesn't know the sword? In general we all know the sword, which in essence, the sword is a sharp weapon that has a long blade, which can be one side sharp or both sides sharp and generally made of hard metal, such as iron, steel, gold to meteorites. According to history, the sword has been made since the bronze age which of course its shape is still very rough and simple. Then it continues until now the various shapes and details are refined. The adaptive analysis method lays down the basic analogy premise of the rule of a "sword". This leads to understanding the understanding of a point as a meeting of two lines of strategy, where the line is a set or collection of points, so that the two strategy lines are a unified line as a grand strategy or referred to as Grand Strategy. This grand strategy consists of two strategies like two sides of a coin that cannot be separated. 
Philosophically, the hand will be injured when holding a sharp knife and vice versa becomes no longer useful when only holding the handle, so holding the handle complete with sharp blades will be useful as the role and function of the sword as needed. So the sword in the sense of two lines connected by a central point $(0 ; 0)$ on the coordinates of the cross axis $(\mathrm{X} ; \mathrm{Y})$, which can be a diagonal line (straight line/angle $180^{\circ}$ or non-straightener/not $180^{\circ}$ angle) as shown in Figure 4.

\subsection{Empirical}

As an empirical process of applying the adaptive analysis method, it is carried out by forming a Discussion Team consisting of 15 academics who are completing Post-graduate Masters studies in the Masters Program from the Indonesian Defense University who also act as respondents, along with 13 other professionals and practitioners as a respondent. Evaluate aspects of SWOT/TOWS, collect data through questionnaires and continue with discussions to find policy strategies that can be recommended as well as advice to policy makers and decision makers. The problem raised is the issue of terrorism which is a global issue that continues to grow until now and as a forecast of the future, the issue of terrorism is still ongoing. Conduct data collection, data processing and discussion in the first week to second week of December 2019, shown in: Figures 5-9; and Table $2 \&$ Table 3.

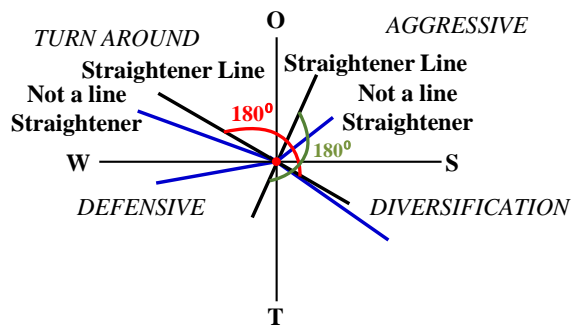

Figure 4. $\mathrm{S}=\mathrm{W}$ and $\mathrm{O}=\mathrm{T}$, Source: data processed by the author.
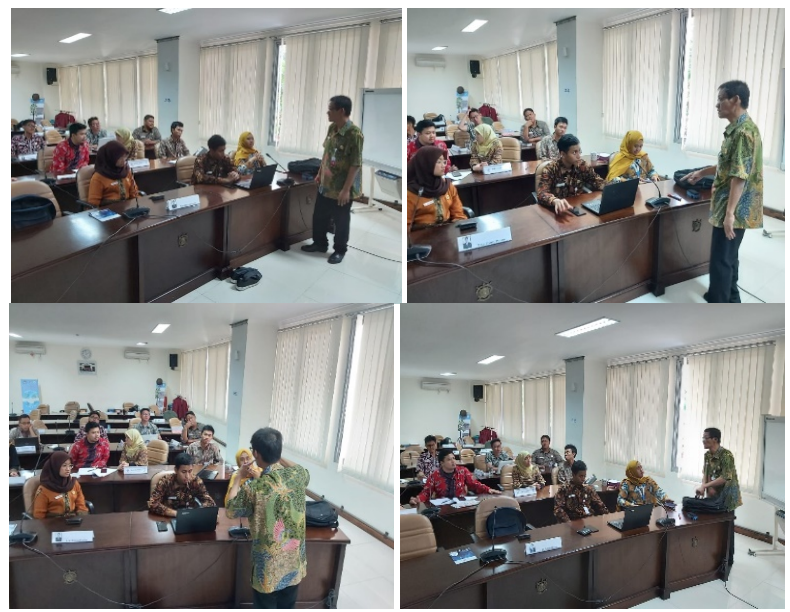

Figure 5. Implementation of the discussion. Source: Data processed by the author and discussion team. 


\section{Recapitulation Data:}

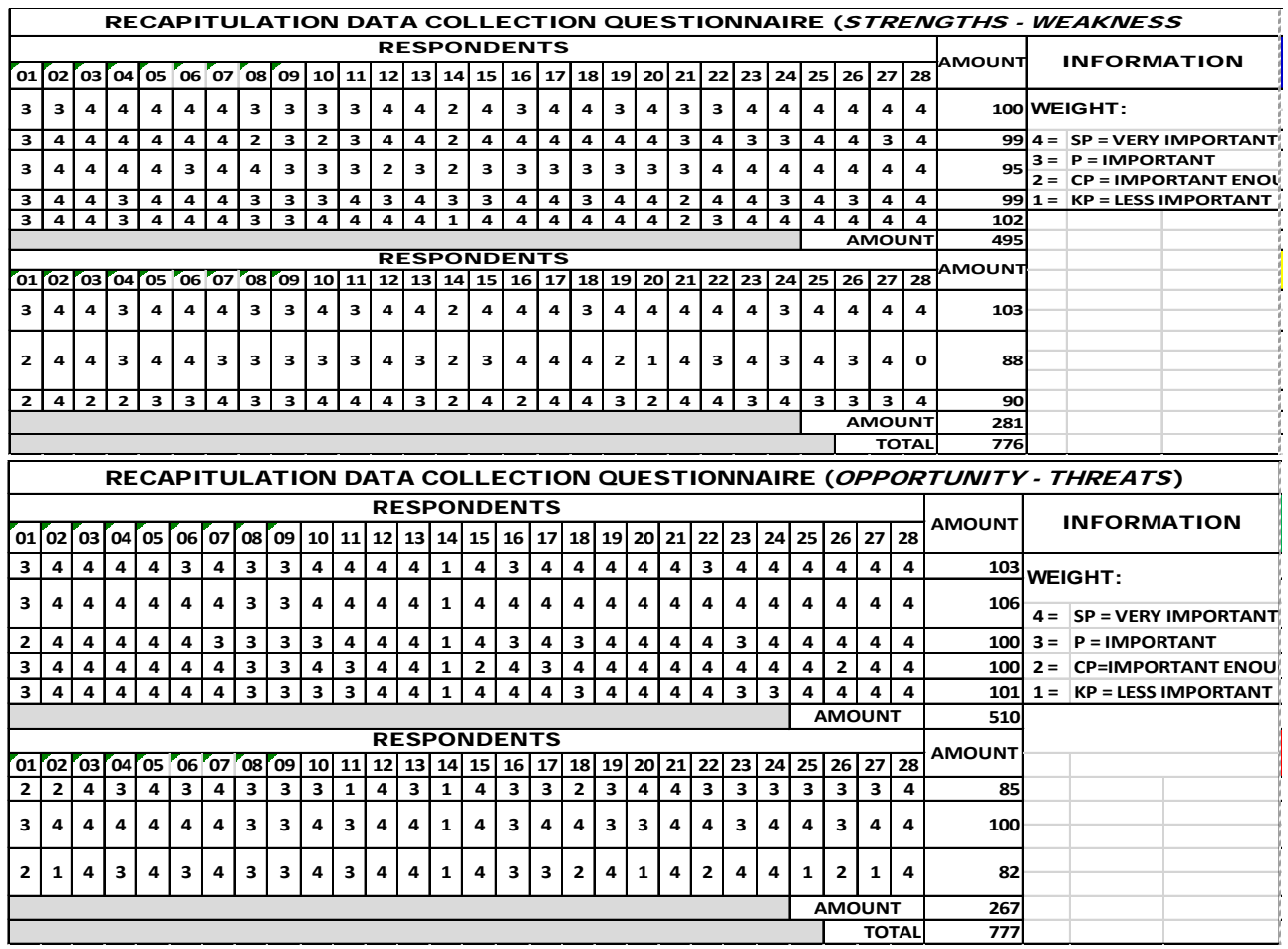

Figure 6. Summary of data collection weight. Source: data processed by the author.

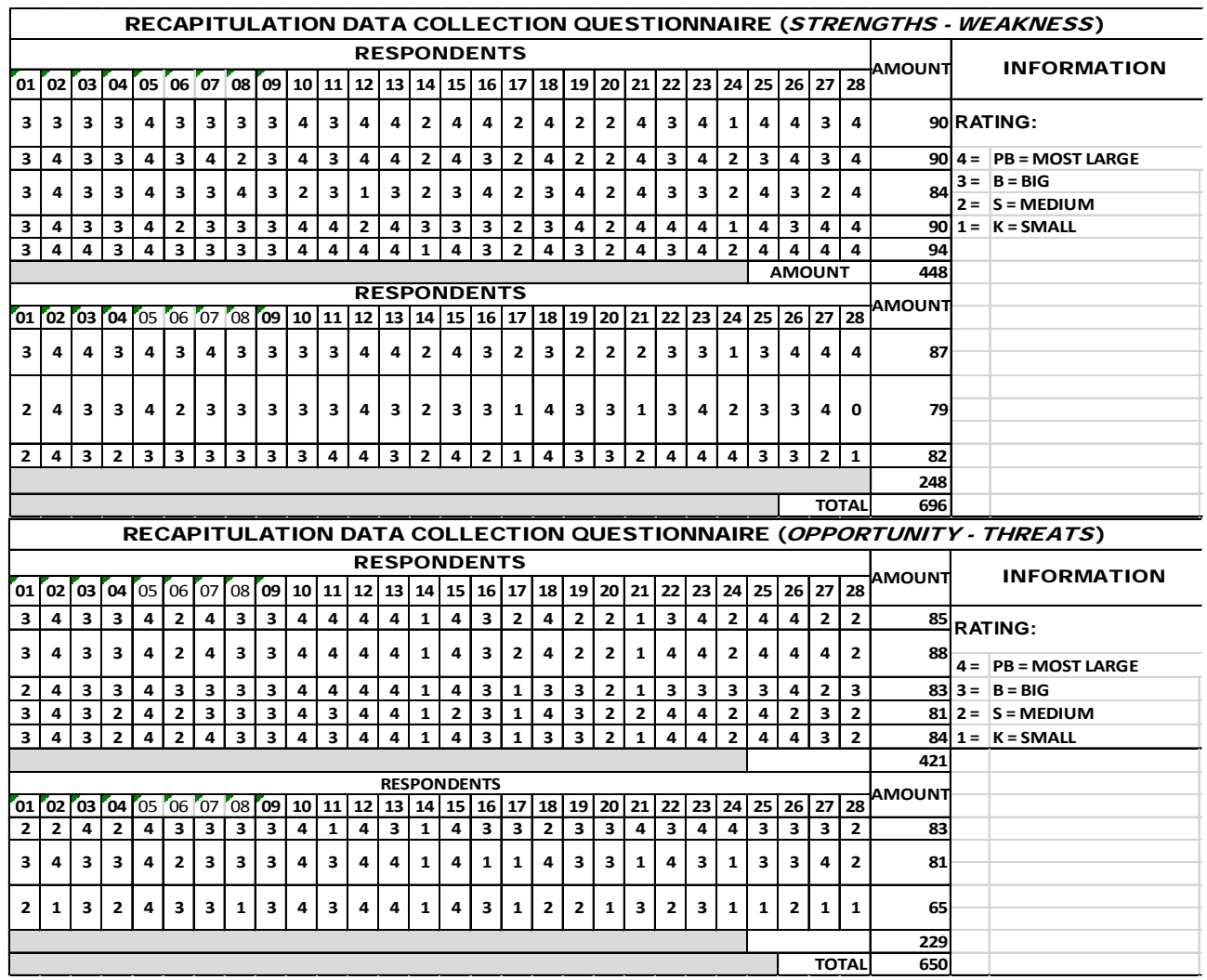

Figure 7. Summary of data collection rating. Source: data processed by the author. 


\begin{tabular}{|c|c|c|c|}
\hline \multicolumn{4}{|l|}{ IFAS DATA PROCESSING } \\
\hline STRENGTHS & WEIGHT & RATING & SCORE \\
\hline $\begin{array}{l}\text { 1. The Government of } \mathrm{dg} \text { all its capabilities and existing resources, implement } \\
\text { decentralization and confront terrorism }\end{array}$ & 0.13 & 3.21 & 0.41 \\
\hline 2.Increasing the role of local government in the face of terrorism & 0.13 & 3.21 & 0.41 \\
\hline $\begin{array}{l}\text { 3. Hold affairs according to the principles of autonomy and } \\
\text { dg assistance task principle of broad autonomy. }\end{array}$ & 0.12 & 3.00 & 0.37 \\
\hline 4. The resources of local governments. & 0.13 & 3.21 & 0.41 \\
\hline $\begin{array}{l}\text { 5. Increase the ability and strength of local governments to ensure the smooth } \\
\text { and successful progress of the region }\end{array}$ & 0.13 & 3.36 & 0.44 \\
\hline AMOUNT & 0.64 & & 2.04 \\
\hline Weakness & WEIGHT & RATING & SCORE \\
\hline $\begin{array}{l}\text { 1. The government can enhance its role in empowerment } \\
\text { defense region in order to confront terrorism? }\end{array}$ & 0.13 & 3.11 & 0.41 \\
\hline $\begin{array}{l}\text { 2. Can prevent local government officials who lack initiative, indifference } \\
\text { And sensitivity of the community as well as other related institutions dg synergies } \\
\text { the entire community in the area.? }\end{array}$ & 0.11 & 2.82 & 0.32 \\
\hline 3. The weakness of governments in the face of terrorism. & 0.12 & 2.93 & 0.34 \\
\hline AMOUNT & 0.36 & & 1.07 \\
\hline TOTAL & 1.00 & & 3.11 \\
\hline \multicolumn{4}{|l|}{ EFAS DATA PROCESSING } \\
\hline OPPORTUNITY & WEIGHT & RATING & SCOR日 \\
\hline 1. Optimizing the role of local government in the face of terrorism? & 0.13 & 3.04 & 0.40 \\
\hline $\begin{array}{l}\text { 2. Create a local government bodies that initiative and creative, people who are } \\
\text { sensitive and synergy agencies, other governments and all people in the region }\end{array}$ & 0.14 & 3.14 & 0.43 \\
\hline 3. Global and regional Banglingstra & 0.13 & 2.96 & 0.38 \\
\hline 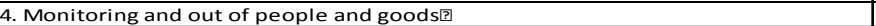 & 0.13 & 2.89 & 0.37 \\
\hline 5. Coordinate and develop synergies between regional hub & 0.13 & 3.00 & 0.39 \\
\hline AMOUNT & 0.66 & & 1.97 \\
\hline THREATS & WEIGHT & RATING & SCORE \\
\hline 1. Can happen if local governments do not develop (stagnant) & 0.11 & 2.96 & 0.32 \\
\hline 2. The rapid technological advances that greatly affect the effort & 0.13 & 2.89 & 0.37 \\
\hline 3. The spirit of dare to die; wanted to liberate themselves; poverty, inequality & 0.11 & 2.32 & 0.24 \\
\hline AMOUNT & 0.34 & & 0.94 \\
\hline TOTAL & 1.00 & & 2.92 \\
\hline
\end{tabular}

Figure 8. (Internal \& External) factor analysis summary table. Source: data processed by the author.

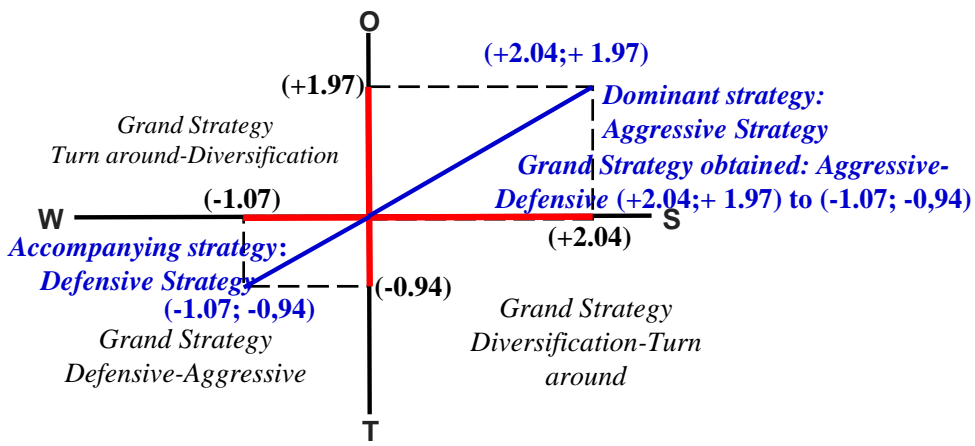

Figure 9. Cross-axis coordinates adaptive analysis. Source: data processed by the author.

Weight of each item in internal and external factors:

Internal: $\frac{\text { Number of weighting given by all respondents }}{\text { Total number of Weights (Strengths + Weakness) }}$

Example: $\mathrm{S} 1=100 / 776=0.129=0.13$

$\mathrm{W} 2=88 / 776=0.113=0.11$

External: Number of weighting given by all respondents

Total number of weights (Opportunity + Threaths)

Example: $\mathrm{O} 2=106 / 777=0.136=0.14$

$\mathrm{T} 3=82 / 777=0.106=0.11$

Rating of each item in internal and external factors: 
Number of ratings given by all respondents

Number of respondents

Example: $\mathrm{S} 1=90 / 28=3.214=3.21$

$$
\begin{aligned}
& \mathrm{W} 2=79 / 28=2.281=2.82 \\
& \mathrm{O} 2=88 / 28=3.143=3.14 \\
& \mathrm{~T} 3=65 / 28=2.321=2.32
\end{aligned}
$$

Obtained: table IFAS $=\mathrm{S}=+2.04$ and $\mathrm{W}=-1.07$ (@ Score $=$ Weight $\times$ Rating) table EFAS $=\mathrm{O}=+1.97$ and $\mathrm{T}=-0.94$ (@ Score $=$ Weight $\times$ Rating)

\begin{tabular}{|c|c|c|c|c|}
\hline Strategy (SO) & Score (S) & Score (O) & Amount & Priority \\
\hline $\mathrm{S} 1+\mathrm{O} 1$ & 0.41 & 0.40 & 0.81 & $\mathrm{~V}$ \\
\hline $\mathrm{S} 1+\mathrm{O} 2$ & 0.41 & 0.43 & 0.84 & II \\
\hline $\mathrm{S} 1+\mathrm{O} 3$ & 0.41 & 0.38 & 0.79 & VII \\
\hline $\mathrm{S} 1+\mathrm{O} 4$ & 0.41 & 0.37 & 0.78 & VIII \\
\hline $\mathrm{S} 1+\mathrm{O} 5$ & 0.41 & 0.39 & 0.80 & VI \\
\hline $\mathrm{S} 2+\mathrm{O} 1$ & 0.41 & 0.40 & 0.81 & $\mathrm{~V}$ \\
\hline $\mathrm{S} 2+\mathrm{O} 2$ & 0.41 & 0.43 & 0.84 & II \\
\hline $\mathrm{S} 2+\mathrm{O} 3$ & 0.41 & 0.38 & 0.79 & VII \\
\hline $\mathrm{S} 2+\mathrm{O} 4$ & 0.41 & 0.37 & 0.78 & VIII \\
\hline $\mathrm{S} 2+\mathrm{O} 5$ & 0.41 & 0.39 & 0.80 & VI \\
\hline $\mathrm{S} 3+\mathrm{O} 1$ & 0.37 & 0.40 & 0.77 & IX \\
\hline $\mathrm{S} 3+\mathrm{O} 2$ & 0.37 & 0.43 & 0.80 & VI \\
\hline $\mathrm{S} 3+\mathrm{O} 3$ & 0.37 & 0.38 & 0.75 & $\mathrm{XI}$ \\
\hline $\mathrm{S} 3+\mathrm{O} 4$ & 0.37 & 0.37 & 0.74 & XII \\
\hline $\mathrm{S} 3+\mathrm{O} 5$ & 0.37 & 0.39 & 0.76 & $\mathrm{X}$ \\
\hline $\mathrm{S} 4+\mathrm{O} 1$ & 0.41 & 0.40 & 0.81 & $\mathrm{~V}$ \\
\hline $\mathrm{S} 4+\mathrm{O} 2$ & 0.41 & 0.43 & 0.84 & II \\
\hline $\mathrm{S} 4+\mathrm{O} 3$ & 0.41 & 0.38 & 0.79 & VII \\
\hline $\mathrm{S} 4+\mathrm{O} 4$ & 0.41 & 0.37 & 0.78 & VIII \\
\hline $\mathrm{S} 4+\mathrm{O} 5$ & 0.41 & 0.39 & 0.80 & VI \\
\hline $\mathrm{S} 5+\mathrm{O} 1$ & 0.44 & 0.40 & 0.84 & II \\
\hline $\mathrm{S} 5+\mathrm{O} 2$ & 0.44 & 0.43 & 0.87 & I \\
\hline $\mathrm{S} 5+\mathrm{O} 3$ & 0.44 & 0.38 & 0.82 & IV \\
\hline $\mathrm{S} 5+\mathrm{O} 4$ & 0.44 & 0.37 & 0.81 & $\mathrm{~V}$ \\
\hline $\mathrm{S} 5+\mathrm{O} 5$ & 0.44 & 0.39 & 0.83 & III \\
\hline
\end{tabular}

Then, the mapping of the cross axis $(\mathrm{X} ; \mathrm{Y})$.

Table 2. Priority of strategy on dominant strategy (SO).

Source: data processed by the Author. 
Table 3. Priority of strategy on accompanying strategy (WT).

\begin{tabular}{ccccc}
\hline Strategy (WT) & Score (W) & Score (T) & Amount & Priority \\
\hline W1 + T1 & 0.41 & 0.32 & 0.73 & II \\
W1 + T2 & 0.41 & 0.37 & 0.78 & I \\
W1 + T3 & 0.41 & 0.24 & 0.65 & VII \\
W2 + T1 & 0.32 & 0.32 & 0.64 & VIII \\
W2 + T2 & 0.32 & 0.37 & 0.69 & IV \\
W2 + T3 & 0.32 & 0.24 & 0.56 & IX \\
W3 + T1 & 0.34 & 0.32 & 0.66 & VI \\
W3 + T2 & 0.34 & 0.37 & 0.71 & III \\
W3 + T3 & 0.34 & 0.24 & 0.68 & V \\
\hline
\end{tabular}

Source: data processed by the Author.

The Grand strategy selected is Aggressive-Defensive (SO-WT), that maximize the power of taking advantage of opportunities to the fullest with regard to minimization of weakness to avoid/minimize the threat. Next determine the strategic priorities of the dominant strategy and accompanying strategy.

The priority strategy of the dominant strategy $\mathrm{SO}$ is (S5-O2) and the priority of the strategy that accompanies WT is (W1-T2). So, the chosen grand strategy is Aggressive-Defensive (SO-WT) with priority strategies (S5-O2 and W1-T2) or (Max-Max and Min-Min), where:

S5 = Adjustment to the dynamics of rapid and dynamic development of the strategic environment in the life of the nation and state of Indonesia by increasing the capability and strength of regional governments to ensure the smooth and successful progress of the region as the implementation of regional government tasks in regional development (national development integralism).

$\mathrm{O} 2$ = Creating an initiative and creative regional government apparatus, a sensitive community and synergy with related institutions such as the TNI (Indonesian Armed Force), Polri (Indonesian Republic Police), Prosecutors and others as well as other local governments together with all communities in the region in the face of terrorism.

$\mathrm{W} 1$ = The government can play an increasing role in empowering the defensive area in order to confront terrorism.

T2 = Rapid technological advances that greatly affect the adjustment ability of governments in the face of terrorism.

The recommended grand strategy is the Aggressive-Defensive with priority (S5O2-W1T2): "Maximizing increased ability and strength of the local government to ensure the smooth and successful advance the region by creating local government officials whose initiative and creative, sensitive community and synergy with related agencies as well as other local collective whole the maximum local communities, through increased local government's role in empowering the defense area to adjust to the rapid technological advancement of local 
government capabilities in the face of terrorism".

Faced with instability, uncertainty, complexity and ambiguity, the control of strengths and weaknesses in the implementation of a control strategy of opportunities and threats as a fact of challenge in the challenge strategy is a phenomenal, natural and relevant fact, so that in the case of the analysis used, the use of adaptive analysis methods is sufficient potential, effective and efficient, because the resulting grand strategy is an analysis of the present (the present analysis) and the future (the future analysis), so it does not have to do two analyzes namely SWOT (the present analysis) and TOWS (the future analysis), but enough with adaptive analysis. Next, based on the recommended policy strategies, the suggested policies: "Increase the ability and strength of the Local Government to ensure the smooth and successful progress of the region, creating an initiative and creative Local Government apparatus, a sensitive and synergistic society, through optimizing the increasing role of the Local Government in empowering defense areas along with technological advancements to avoid the Local Government inability to face the threat of terrorism".

\section{Conclusions}

Adaptive analysis method is a simple analysis method, but from the simplest thing, sometimes it is unthinkable. Likewise, the SWOT/TOWS analysis is also simple; in fact the application of SWOT/TOWS analysis generally results in several options that may be considered by some to be alternatives, so that efforts to obtain more choices and priorities are carried out and that also results in some experiencing a popular misunderstanding of the application of the SWOT analysis and TOWS.

The adaptive analysis method is a new analysis method, which is a SWOT analysis dynamism using commutative properties with the application of the operation of the sign on the cross axis coordinate number line (X; Y), based on the line theory and rules of a sword, to obtain a chosen grand strategy containing a dominant strategy and the accompanying strategy as a unified strategy like two sides of a coin.

This adaptive method of analysis is phenomenal, natural and relevant as the optimal approach to achieve something better as expected goals. Furthermore, the adaptive analysis method can be implemented on various purposes, such as case study analysis, situation analysis, organizational analysis and others.

\section{Conflicts of Interest}

The author declares no conflicts of interest regarding the publication of this paper.

\section{References}

[1] Rangkuti, F. (2014) SWOT Analysis, Techniques for Dissecting Business Cases. 18th 
Edition, PT Gramedia Pustaka Utama, Jakarta, Indonesia, 19.

[2] Philip Kotler, D.K. (2009) Marketing Management. Indeks, Jakarta, 63.

[3] Akdon (2009) Strategic Management for Education Management. Alfabeta, Bandung, 34.

[4] Rusdiyanto, I. (2002) The Art of War Niccolo Machiavelli. Prawacana 9-17, Narration in Collaboration with Promethea Literature, Jakarta.

[5] Pratama, R. (2009) 108 Tactics for Living the SunTzu Life. First Print 2009, Wahana Totalita Publisher, Sleman, DIY, Indonesia.

[6] Group, T.D. (2003) The Art of War. Lucky Publisher, Batam, 46.

[7] KBBI Online (2019). https://kbbi.web.id/analysis https://kbbi.web.id

[8] Dumairy (1991) Applied Mathematics for Business and Economics. 2nd Edition, BPFE-Yogyakarta, Yogyakarta, DIY, 16, 19. 